\title{
La agrotecnología no se detiene
}

\section{Agrotechnology does not stop}

${ }^{1}$ Cerna Mendoza, Agustín ${ }^{[0000-0002-4827-9966]}$

${ }^{1}$ Universidad Nacional de San Martín, Tarapoto, Perú

\section{Editorial}

acerna@unsm.edu.pe

La Universidad Nacional de San Martin tiene como ámbito de intervención a la región San Martín (UNSM-T, 2019); comprende parte de selva alta, la cordillera occidental y una zona transicional de la llanura Amazónica, con recursos forestales, de fauna, de suelo y cuatro valles productivos constituidos por el Alto Mayo, Bajo Mayo, Huallaga Central y Alto Huallaga formados por los ríos Mayo y Huallaga (Mincetur, 2020). Las actividades agropecuarias se sustentan en los cultivos de palma aceitera, arroz, maíz amarillo duro, yuca, tabaco, cacao, café, naranja, coco, plátano, sacha inchi y otros cultivos preservados por las comunidades nativas con utilidad alimenticia y medicinal. La actividad pecuaria está basada principalmente en la crianza de ganado vacuno, porcino y aves de corral (MINAGRI, 2019).

Es importante destacar que la región San Martín es eminentemente agrícola, pecuaria y forestal y facultades como Agronomía, Ingeniería Agroindustrial y Ecología tienen el reto de formar recursos humanos competitivos, así como ampliar y difundir el conocimiento científico mediante la publicación de artículos científicos (Piedra \& Martínez, 2007).

La región San Martín tiene una participación activa en la industria de la madera, arroz, aceites, destilerías y otras manufacturas artesanales dedicadas a la transformación de los productos agrícolas (Rosemberg, 2018). Estos bastos recursos, constituyen el laboratorio natural donde los investigadores de la UNSM desarrollan proyectos de investigación e innovación en áreas de las ciencias biológicas, agrícolas, pecuarias, forestales, sociales, culturales, climáticas, etc.; a través de sus líneas de investigación generadas como ejes temáticos (Goresam, 2020).

Como homenaje a los 41 años de vida de nuestra institución y con gran satisfacción presentamos el primer número de la Revista Agrotecnológica Amazónica, la misma que con una edición semestral servirá como estrategia de difusión del conocimiento científico generado en nuestra región. En esta primera publicación, ponemos a disposición 05 artículos científicos, como una contribución de nuestros investigadores.

\section{Dr. Agustín Cerna Mendoza \\ Investigador Calificado RENACYT-CONCYTEC \\ Coeditor de la Revista \\ Facultad de Ciencias Agrarias \\ Universidad Nacional de San Martín}




\section{Referencias bibliográficas.}

GORESAM. (2020, January 15). Ganaderos ya pueden acceder a semen fresco en la Granja de

Calzada. https://www.regionsanmartin.gob.pe/Noticias?url=noticia\&id=5861

MINAGRI. (2019). Anuario Estadístico de la Producción Ganadera y Avícola 2019.

http://siea.minagri.gob.pe/siea/?q=publicaciones/anuario-de-produccion-pecuaria

Mincetur. (2020). San Martín: Reporte de Comercio Primer Semestre - 2019.

Piedra, Y., \& Martínez, A. (2007). Producción científica. Ciencias de La Información, 38(3),

33-38. http://www.redalyc.org/pdf/1814/181414861004.pdf

Rosemberg, M. (2018). La ganadería bovina en Perú . Veterinaria Digital.

https://www.veterinariadigital.com/articulos/la-ganaderia-bovina-en-peru

UNSM-T. (2019). Universidad Nacional de San Martín - Tarapoto. https://unsm.edu.pe/ 